\title{
Genetic evaluation of the Iberian lynx ex situ conservation programme
}

\author{
Daniel Kleinman-Ruiz ${ }^{1}$ Laura Soriano ${ }^{1} \cdot$ Mireia Casas-Marce ${ }^{1} \cdot$ Charles Szychta $^{1} \cdot$ Iñigo Sánchez $^{2}$. \\ Jesús Fernández ${ }^{3}$. José A. Godoy ${ }^{1}$
}

Received: 13 November 2018 / Revised: 8 March 2019 / Accepted: 11 March 2019 / Published online: 5 April 2019

(c) The Genetics Society 2019

\begin{abstract}
Ex situ programmes have become critical for improving the conservation of many threatened species, as they establish backup populations and provide individuals for reintroduction and reinforcement of wild populations. The Iberian lynx was considered the most threatened felid species in the world in the wake of a dramatic decline during the second half of the 20th century that reduced its numbers to around only 100 individuals. An ex situ conservation programme was established in 2003 with individuals from the two well-differentiated, remnant populations, with great success from a demographic point of view. Here, we evaluate the genetic status of the Iberian lynx captive population based on molecular data from 36 microsatellites, including patterns of relatedness and representativeness of the two remnant genetic backgrounds among founders, the evolution of diversity and inbreeding over the years, and genetic differentiation among breeding facilities. In general terms, the ex situ population harbours most of the genetic variability found in the two wild populations and has been able to maintain reasonably low levels of inbreeding and high diversity, thus validating the applied management measures and potentially representing a model for other species in need of conservation.
\end{abstract}

\section{Introduction}

Human activity is driving species to extinction at exceptionally high rates (Pimm et al. 2014). Ever-growing threats to biodiversity, such as overexploitation, habitat destruction, and pervasiveness of invasive species (Wilson 1992), pose a challenging ordeal for species persistence (Butchart et al. 2010). At the same time, it is becoming evident that conservation actions can have a positive impact (Hoffmann

Supplementary information The online version of this article (https:// doi.org/10.1038/s41437-019-0217-z) contains supplementary material, which is available to authorized users.

$\square$ José A. Godoy

godoy@ebd.csic.es

1 Departamento de Ecología Integrativa, Estación Biológica de Doñana (EBD-CSIC), Calle Americo Vespucio 26, 41092 Sevilla, Spain

2 Zoobotánico Jerez, Calle Madreselva s/n, 11408 Jerez de la Frontera, Spain

3 Departamento de Mejora Genética Animal, INIA, Carretera de la Coruña Km. 7, 28040 Madrid, Spain et al. 2010). In situ conservation is the main focus of biological conservation based on the multiple benefits derived from the integrated protection of habitats and ecosystems. However, in the current scenario of rapid climate change and increased habitat destruction, reliance solely on in situ approaches may not ensure the long-term-or, under critical scenarios, even the short-term- persistence of many species. In contrast, the potential of ex situ conservation, once relegated to educational, research and fund-raising roles (Pritchard et al. 2012), to contribute more directly to biological conservation is rapidly increasing, thanks to improved global coordination, infrastructures, technical knowledge and practices (Pritchard et al. 2012; Redford et al. 2012).

Captive populations act as an insurance reserve, in case disaster strikes wild populations. Individuals in captive populations are protected from threats such as predation and poaching, they are subject to continuous surveillance and they can receive timely medical assistance. As collateral benefits, ex situ programmes provide valuable insights into species' biology by supporting and enhancing research on behaviour, reproduction and physiology, among others (McGowan et al. 2017). Indeed, ex situ conservation has played a major role in the improved conservation of many 
vertebrate species, including the California condor (Gymnogyps californianus), Arabian oryx (Oryx leucoryx), whooping crane (Grus americana) and blackfooted ferret (Mustela nigripes) (Hoffmann et al. 2010). Still, ex situ conservation should be regarded as an additional means of preserving species, so whenever possible, it should be the source for individual reintroductions into the wild and be part of an integrative approach to species-wide management in conjunction with in situ actions (Russello and Amato 2007; Pritchard et al. 2012; Redford et al. 2012; McGowan et al. 2017).

More importantly, captive populations can be used to boost genetic diversity and minimise inbreeding through managed and monitored admixture of differentiated remnant populations when available. This is particularly relevant since species under extinction risk are often genetically eroded (i.e., show loss of genetic diversity and accumulation of inbreeding), as the consequence of species decline and fragmentation. However, captive populations-which are generally founded by a small number of individuals, are usually small themselves, and have an environment different from wild - carry their own additional genetic risks, namely: (i) loss of genetic diversity, (ii) accumulation of inbreeding, (iii) incidence of genetic diseases and other deleterious traits, and (iv) adaptation to captivity (Frankham 2008; Frankham et al. 2010).

Genetic risks in captivity, though, can be somewhat ameliorated through adequate genetic management. Towards this goal, the commonly recommended and optimal strategy (as proven both theoretically and by simulations) is based on the minimisation of average kinship (Ballou and Lacy 1995; Meuwissen 1997; Fernández and Toro 1999; Caballero and Toro 2000; Fernández et al. 2004). The implementation of the minimum kinship strategy has traditionally been based on studbook records and pedigree analyses (Ballou et al. 2010). However, molecular data can assist and improve genetic management by assessing the representativeness of founders, detecting studbook errors and, most importantly, unravelling the typically unknown relatedness among founders. By doing so, they allow for higher accuracy in routine tasks, such as identifying optimal breeding pairs, exchanging individuals between facilities or selecting suitable candidates for reintroduction (Frankham et al. 2010).

Of the four extant species in the lynx genus, the Iberian lynx (Lynx pardinus) has the smallest distribution area and population size. During the second half of the 20th century, the species underwent a drastic decline that saw the majority of its populations become extinct in the span of five decades (Rodríguez and Delibes 1992, 2002; Calzada et al. 2007). By 2002, less than 100 individuals remained, distributed among two isolated populations in Andalusia (southern Spain): a peripheral population in the protected area of
Doñana (DON) and a central one in Sierra de Andújar in the Sierra Morena range (AND). Separated by ca. $240 \mathrm{~km}$, the two populations have been effectively isolated for almost two centuries (ca. 40 generations), until the start of translocations in 2007 (Guzmán et al. 2004; Casas-Marce et al. 2017). This scenario led to the recognition of the Iberian lynx as the most endangered felid in the world (Nowell and Jackson 1996) and to its classification as "critically endangered" in the 2002 and 2008 IUCN red lists (Rodríguez and Calzada 2015).

Genetic erosion in the Iberian lynx has been well documented. Studies based on the mitochondrial, microsatellite and genome-wide data have revealed a high inbreeding rate, high differentiation between the two populations, and extremely low whole-genome level diversity $(\pi=0.026 \%$ ), which is among the lowest ever reported-in the same ballpark as that of the cheetah (Acinonyx jubatus) and notably lower than that of other felids and humans (Johnson et al. 2004; Palomares et al. 2012; Casas-Marce et al. 2013; Dobrynin et al. 2015; Abascal et al. 2016). Moreover, several observations indicative of inbreeding depression have been reported, including an increase in the proportion of the abnormal sperm with individual inbreeding (RuizLópez et al. 2012), a decrease in survival and litter size in DON (Palomares et al. 2012), a trend that may have reversed following translocations (Simón et al. 2012), and a high incidence of membranous glomerulonephritis and lymphoid depletion (Peña et al. 2006; Jiménez et al. 2008). Besides, a number of deleterious traits believed to have a genetic basis are currently segregating at moderate frequencies in the captive population (Martínez et al. 2013).

Such a negative outlook encouraged the implementation of active conservation measures with the main funding coming from four successive European LIFE projects in the period 1994-2018 (Simón et al. 2012). In situ actions have included the improvement of natural habitats, an increase of prey abundance, the reduction of non-natural mortality, the reconnection of the two remnant populations through translocations and awareness-raising measures, to name a few (Simón et al. 2012). In parallel, an ex situ breeding programme was established in 2003 with the specific goals of: (i) maintaining a genetically and demographically managed captive population that encompasses and safeguards the extant genetic diversity present in the two wild populations; and (ii) providing individuals for reintroduction programmes aiming to recover the species' historical distribution in Spain and Portugal (Vargas et al. 2008; Vargas, Breitenmoser, et al. 2009; Vargas, Rivas, et al. 2009).

The initial Iberian lynx captive population was founded with animals from the two genetically differentiated populations. Genotypes for 36-microsatellite markers (Godoy et al. 2009; Casas-Marce et al. 2013) have been routinely 
used to estimate the unknown relatedness among founders, which then informs the pedigree-based kinship minimisation management strategy. On a yearly basis, a list with the optimal contributions and mating pairs is developed for each centre, becoming the blueprint on which crosses are attempted. Every few years, translocations of animals between facilities take place to avoid reduced diversity within centres and differentiation between them. Finally, since 2010, when carrying capacity was reached, most captive-born animals have been released at reintroduction sites. The selection and distribution of animals among reintroduction sites have also been informed by minimum average kinships.

Global conservation efforts have helped to recover the number of free-living lynx to over the 500-individual milestone (589 in the latest census from 2017; http://www. iberlince.eu/images/docs/3_InformesLIFE/Informe_Censo_ 2017.pdf), which has resulted in the downlisting of the species from "Critically Endangered" to "Endangered" in the 2015 International Union for Conservation of Nature (IUCN) Red List (Rodríguez and Calzada 2015).

The aim of this study is to evaluate the genetic status of the captive Iberian lynx population based on pedigree and genotype data for 36 microsatellites. We specifically aim to answer the following questions: (i) how well is the genetic diversity of wild populations represented by founders, and (ii) how have diversity and genetic structure statistics changed over the years, as measured by marker- and pedigree-based analyses. In short, we evaluate how successful the Iberian lynx ex situ programme has been from a genetic point of view.

\section{Materials and methods}

\section{Populations}

Here, we studied the captive population (CAP) of Iberian lynx from its conception up to 2015. For most analyses, captive individuals were categorised into two groups: wildborn founders (from here on CAP-WB) belonging to either the DON (CAP-WB-DON) or the AND (CAP-WB-AND) populations, and captive-born (CAP-CB).

The Iberian lynx ex situ programme was founded in 2003 with seven CAP-WB individuals that had been captured starting in 2001, and up to 50 have since been recruited (Supplementary Figure S1a). Currently, the programme comprises four main breeding facilities: (i) El Acebuche, located within the boundaries of Doñana National Park (Andalusia, Spain), with 18 enclosures; (ii) Centro Nacional de Reprodução de Lince Ibérico, in Silves (Algarve, Portugal), with 16 enclosures; (iii) Granadilla, located north of
Cáceres (Extremadura, Spain), also with 16 enclosures and (iv) La Olivilla, in Santa Elena (Andalusia, Spain), with 23 enclosures. Five additional enclosures in the Zoobotánico Jerez facility, in Jerez de la Frontera (Andalusia, Spain), complete the breeding network (https://www.lynxexsitu.es/ programa-en.php?sec $=$ centro).

For the yearly analyses, two different sets of criteria were adopted to define the yearly datasets based on a version of the studbook dated the 21st of April, 2017 (Supplementary Table S1). Yearly cohorts include CAP-CB individuals born in the year (typically between March and May) that were still alive on the 1 st of November (i.e., only each year's surviving newborns were included; Supplementary Figure S1b). Yearly censuses include all living captive individuals on the 1st of November of each year (Supplementary Figure S1c).

In addition, free-living wild-born individuals (FRL-WB) coming from the remnant populations of AND (FRL-WBAND) and DON (FRL-WB-DON) were used for comparison with CAP-WB individuals. A map showing the location of both remnant populations as well as the breeding facilities is provided in Supplementary Figure S2.

\section{Samples and DNA extraction}

A total of 239 captive individuals, sampled during routine checkups or necropsies between 2003 and 2015, were genotyped for this study, including an exhaustive sampling of wild-born individuals (49 out of 50 CAP-WB individuals; the unsampled one died before contributing any descendants). Thirty-six of these individuals were of pure AND genetic background, nine of pure DON genetic background and the remaining four, which were born in the DON population following translocations of AND animals, were first backcrosses to DON individuals (descendants of DON $\times F_{1}$ matings). With regard to the 190 CAP-CB individuals, the sampling was comprehensive until 2011, with the exception of some rare cases of abortions and a few other individuals that died before breeding. From 2012 to 2015 , the genotyped samples covered between $63 \%$ and $94 \%$ of each year's cohort.

Whole blood from living animals was mixed with four volumes of lysis buffer $(0.1 \mathrm{M}$ Tris- $\mathrm{HCl}, \mathrm{pH} 8.0 ; 0.1 \mathrm{M}$ Na-EDTA; $0.01 \mathrm{M} \mathrm{NaCl}, 0.5 \%$ SDS), immediately after collection and stored at $4{ }^{\circ} \mathrm{C}$. Tissue samples (mainly muscle) from dead animals were frozen and kept at $-80^{\circ} \mathrm{C}$. DNA was extracted from all samples using standard phenol-chloroform methods (Sambrook and Russell 2006).

As for the remnant populations, genotypes previously reported in Casas-Marce et al. (2013) from a total of 50 FRL-WB-DON and 54 FRL-WB-AND individuals were used to gauge representativeness of CAP-WB individuals. 


\section{Microsatellite genotyping}

Samples were genotyped for 36 heterospecific microsatellite loci as previously reported (Casas-Marce et al. 2013). Fluorescently labelled products were amplified in separate PCRs containing $1 \times$ Bioline PCR buffer, $2 \mathrm{mM} \mathrm{MgCl}_{2}$, $0.25 \mathrm{mM}$ dNTPs, $0.01 \mathrm{mg} / \mathrm{mL}$ BSA, $0.4 \mu \mathrm{M}$ of each primer, $0.4 \mathrm{U}$ of Bioline Taq polymerase and $50 \mathrm{ng}$ of the template in a total volume of $14 \mu \mathrm{L}$ and were run for 2 min at $92^{\circ} \mathrm{C}$, followed by 39 cycles of $30 \mathrm{~s}$ at $92^{\circ} \mathrm{C}, 30 \mathrm{~s}$ at $55^{\circ} \mathrm{C}$ and $30 \mathrm{~s}$ at $72{ }^{\circ} \mathrm{C}$, and a final extension of $5 \mathrm{~min}$ at $72{ }^{\circ} \mathrm{C}$. Products were analysed in an ABI $3130 \times 1$ Genetic Analyzer (Applied Biosystems), and the scoring of alleles was carried out using GENEMAPPER, version 3.7 software (Applied Biosystems).

A previous study of wild populations did not yield evidence of null alleles, high error rates or deviations from Hardy-Weinberg equilibrium for both populations for any of the markers (Casas-Marce et al. 2013). Here, we used the software CERVUS 3.0.7 (Marshall et al. 1998; Kalinowski et al. 2007) and the completely known ex situ pedigree to tally Mendelian inconsistencies across all 190 CAP sire-dam-offspring triads as a proxy for error rate. All genotypes obtained in this study are reported in Supplementary Table S2.

\section{Molecular data analyses}

\section{Genetic diversity and differentiation}

With the aim of comparing wild and captive genetic variation, genetic diversity statistics were estimated in $\mathrm{R}$ (The $\mathrm{R}$ Core Team 2015) using the PopGenReport package (Adamack and Gruber 2014), including observed $\left(\mathrm{H}_{\mathrm{O}}\right)$ and expected heterozygosity $\left(\mathrm{H}_{\mathrm{E}}\right)$, mean number of alleles per locus (NA) and allelic richness (AR; the average number of alleles per locus rarefied to the smallest number of alleles seen in a sample across all combinations of population and locus). These statistics were obtained for the CAP population, CAP-WB individuals, subsets that included only pure captive individuals born in Doñana (CAP-WB-DON) or Andújar (CAP-WB-AND) and the aforementioned FRLWB-DON and FRL-WB-AND populations. $\mathrm{F}_{\mathrm{IS}}$ (population inbreeding coefficient) values were estimated with FSTAT v2.9.3 (Goudet 1995, 2002). Four admixed (backcross DON) CAP-WB-DON individuals were excluded from most analyses pertaining to founders. Significance of differences in average $\mathrm{H}_{\mathrm{O}}, \mathrm{H}_{\mathrm{E}}, \mathrm{N}$ and $\mathrm{AR}$ between CAP-WB and FRL-WB individuals were tested for both DON and AND using a two-tailed paired Wilcoxon signed-rank test. To illustrate the distribution of alleles between these two groups, Venn diagrams were drawn using the $\mathrm{R}$ package VennDiagram (Chen and Boutros 2011) for all observed alleles and for a reduced dataset in which all alleles with a single occurrence were pruned out.

We assessed differentiation between the CAP-WB sets and their respective source FRL-WB population for each locus and across loci by estimating $\mathrm{F}_{\mathrm{ST}}$ (Weir and Cockerham 1984), as implemented in FSTAT and Jost's D (Jost 2008) as given by PopGenReport. In addition, we obtained $\mathrm{F}_{\mathrm{ST}}$ values and $99 \%$ confidence intervals among the four main breeding centres (A, S, G and $\mathrm{O}$ ) at the end of our sampling period (year 2015). We considered significant those $\mathrm{F}_{\mathrm{ST}}$ values that did not include zero in their $99 \%$ confidence interval.

We also estimated the variation over time in $\mathrm{H}_{\mathrm{O}}$ and $\mathrm{H}_{\mathrm{E}}$, per locus and across loci, for CAP-CB individuals (cohorts approach) or for the whole CAP population as well as the CAP-WB and CAP-CB subsets of individuals (census approach) using the advanced frequency-based analysis module in GENALEX 6.5 (Peakall and Smouse 2012). To assess the evolution of inbreeding, we estimated $F_{I S}$ for CAP-CB individuals (cohorts and census approaches) and the whole CAP population (census approach).

\section{Relatedness and relationships}

A two-step approach was used for the estimation of relatedness (R) between CAP-WB individuals from molecular marker genotypes. First, we used the weighted equal drift similarity (WEDS) estimator proposed by Oliehoek et al. (2006) and implemented in the software REA v0.2, with the option of $\beta 2$ correction. The WEDS estimator adjusts observed molecular similarities so that the increase in coancestry since the base population is equal at all loci. The $\beta 2$ correction regresses relatedness estimates to their mean using $\beta 2$ (the regression coefficient of pedigree relatedness on estimated relatedness) empirically predicted from the amount of molecular information. The corrected WEDS estimator was shown to conserve a higher proportion of diversity than other estimators under an optimal contribution scheme, particularly so in structured populations (Oliehoek et al. 2006). However, kinships estimated with this method do not range from zero to one as expected for a true kinship. Thus, we also used the methodology implemented in the software MOLCOANC v3.0 (Fernández and Toro 2006) to obtain a congruent kinship matrix. This software creates a virtual genealogy for the founders in such a way that the correlation between the genealogical kinship calculated from that virtual pedigree has the highest correlation with a provided matrix (the one from REA v0.2 in our case). The methodology is able to account for any a priori known relationship (e.g., a couple of individuals sharing a parent) and to detect Mendelian incompatibilities in the proposed families. The number of generations above the founders was set to three, which provided a correlation between matrices of around $98 \%$. Any time a new 
founder is added to the ex situ population the kinship matrix is re-evaluated in order to accommodate the relationships of the new incorporation.

In addition, with the aim of assessing the occurrence of close relatives among founders from the same population, we used the software ML-RELATE (Kalinowski et al. 2006) to calculate maximum likelihood estimates of relatedness and relationship, to compare between alternative relationship categories (PO: parent-offspring; FS: full-siblings; HS: half-siblings; UR: unrelated) and to identify a "confidence set" of categories for each pair of individuals. On the basis of the latter, we conservatively considered as related only those pairs for which the $95 \%$ confidence set did not include the UR category, as unrelated those with only UR included in the set, and as ambiguous those with any combination of unrelated and related categories. For this purpose, we analysed only intra-population pairs using the empirical allele frequencies of each population, so that these estimates reflect only the most recent genealogy.

\section{Pedigree analyses}

Pedigree analyses for a version of the studbook dated the 21st of April, 2017 (Supplementary Table S1) were carried out with the software Population Management x (PMx; Lacy et al. 2012). We estimated values for gene diversity (GD; measured as the reduction in $\mathrm{H}_{\mathrm{E}}$ with respect to the founding population) and mean inbreeding $(\mathrm{F})$ over time taking into account or not the kinships among founders (empirical kinships ON vs. empirical kinships OFF, respectively), which were estimated from molecular marker data as detailed in the previous section.

\section{Optimal and realised ancestry proportions among founders and theoretical maximum $\mathrm{H}_{E}$}

We estimated the optimal proportion of founders (i.e., the contribution of each genetic stock to the pool that would maximise its genetic diversity) following the equation on page 1369 of Toro and Caballero (2005), and on the basis of the genetic diversity within and Nei's minimum distance (Nei 1973) between the two remnant populations empirically estimated from microsatellite genotypes. We often refer to the $\mathrm{H}_{\mathrm{E}}$ of this ideal mix as the theoretical maximum $\mathrm{H}_{\mathrm{E}}$, and use it as a reference point to gauge the actual estimated $\mathrm{H}_{\mathrm{E}}$.

For comparison purposes, we also inferred from the census the actual proportion of CAP-WB individuals from each pool each year, as well as the proportion of contributing founders (defined as those CAP-WB individuals that had offspring before the end of 2017). For all practical purposes, CAP-WB individuals coming from a first backcross of an $F_{1}$ individual with an individual of DON ancestry contributed to calculations as $0.75 \mathrm{DON}$ and 0.25 AND founders.

\section{Results}

\section{Genotyping}

All samples were genotyped at a minimum of 25 (out of the 36 total) loci, with $96 \%$ of them genotyped at 30 or more. Thus, no sample was discarded because of a high proportion of missing data. The proportion of genotypes with Mendelian inconsistencies across all CAP sire-dam-offspring trios in the dataset was $1.35 \%$, indicating a low overall error rate.

\section{Comparing wild and captive genetic variation}

\section{Genetic diversity and differentiation}

Average number of alleles observed per locus for CAP (3.81; range: 2-11) was similar to previously reported values for wild populations (3.75; Casas-Marce et al. 2013), although the average $\mathrm{H}_{O}$ was higher (0.509; range: $0.103-0.792)$ than in any of the remnant populations $(0.313$ and 0.467 in FRL-WB-DON and FRL-WB-AND, respectively), as expected for an admixed population (Table 1). As previously reported for FRL-WB (Casas-Marce et al. 2013), the genetic diversity of CAP-WB-AND was higher than that of CAP-WB-DON (Casas-Marce et al. 2013). We found no significant differences in any of the diversity statistics in comparisons between CAP-WB-AND and FRL-WB-AND populations (Wilcoxon test: $P>0.05$ ), but NA and AR were significantly lower in CAP-WB-DON than in FRL-WBDON $\left(P<0.012\right.$ and $P<1.226 * 10^{-06}$, respectively $)$.

The sets of alleles in each pool of CAP-WB individuals and in their respective FRL-WB population were largely overlapping, more so for AND (where only two and three alleles were private to the FRL-WB and CAP-WB populations, respectively) than for DON (where 12 alleles sampled in FRL-WB were not represented in CAP-WB, and one was exclusive to the latter). Differences between FRL-WB and CAP-WB sets were noticeably reduced when alleles with only one occurrence (singletons, most likely arising from genotyping errors or mutations) were ignored: only one and three alleles were private to FRL-WB-AND and FRL-WB-DON populations, respectively, and none was private to the CAP-WB population (Fig. 1).

Finally, genetic differentiation was extremely low between CAP-WB-DON and FRL-WB-DON populations $\left(\mathrm{F}_{\mathrm{ST}}=-0.001 ; 99 \% \mathrm{CI}[-0.022\right.$ to 0.029$\left.]\right)$, and even lower for AND $\left(\mathrm{F}_{\mathrm{ST}}=-0.009 ; 99 \%\right.$ CI $[-0.011$ to -0.006$\left.]\right)$. 

differentiation statistics
Table 1 Genetic diversity and

\begin{tabular}{llllll}
\hline Population & FRL-WB-DON & CAP-WB-DON & FRL-WB-AND & CAP-WB-AND & $\begin{array}{l}\text { CAP } \\
N\end{array}$ \\
\hline 50 & 9 & 54 & 36 & 239 \\
\hline $\mathrm{H}_{\mathrm{E}}$ & $0.294 \pm 0.037$ & $0.300 \pm 0.038$ & $0.454 \pm 0.030$ & $0.460 \pm 0.031$ & $0.510 \pm 0.026$ \\
$\mathrm{H}_{\mathrm{O}}$ & $0.313 \pm 0.041$ & $0.358 \pm 0.047$ & $0.467 \pm 0.034$ & $0.466 \pm 0.035$ & $0.509 \pm 0.027$ \\
$\mathrm{NA}$ & $2.250 \pm 0.134$ & $1.944 \pm 0.119^{*}$ & $3.306 \pm 0.202$ & $3.333 \pm 0.203$ & $3.806 \pm 0.308$ \\
$\mathrm{AR}$ & $1.890 \pm 0.101$ & $1.874 \pm 0.108^{* *}$ & $2.700 \pm 0.131$ & $2.739 \pm 0.135$ & $2.907 \pm 0.144$ \\
$\mathrm{~F}_{\mathrm{IS}}$ & $-0.054[-0.093,0.015]$ & $-0.135[-0.216,-0.039]$ & $-0.02[-0.058,0.016]$ & $0.002[-0.057,0.053]$ & $0.003[-0.019,0.022]$ \\
$\mathrm{F}_{\mathrm{ST}}$ & $-0.001[-0.018,0.021]$ & & $-0.009[-0.010,-0.007]$ & $\mathrm{NA}$ \\
$\mathrm{D}$ & $-0.003 \pm 0.006$ & & $-0.009 \pm 0.001$ & & $\mathrm{NA}$ \\
\hline
\end{tabular}

$N$ number of genotyped individuals, $H_{E}$ expected heterozygosity, $H_{O}$ observed heterozygosity, $N A$ mean number of alleles per locus, $A R$ allelic richness, $F_{I S}$ population inbreeding coefficient, $F_{S T}$ Weir \& Cockerham's fixation index, $D$ Jost's genetic distance, $C A P$ captive population, $C A P-W B$ captive wild-born individuals, $F R L-W B$ free-living wild-born individuals, $D O N$ Doñana, $A N D$ Andújar

AR was rarefied to the smallest number of alleles seen in any of the five populations (16 alleles). Asterisks accompanying CAP-WB diversity statistics denote significant differences when compared with the respective FRL-WB population using a two-tailed paired Wilcoxon signed-rank test $(* P<0.012$, $* * P<$ $\left.1.226 \cdot 10^{-06}\right)$. $\mathrm{F}_{\mathrm{ST}}$ was estimated for the comparison between each CAP-WB group and its respective FRLWB population. Standard error is given for the diversity statistics, and $95 \%$ confidence interval for the $\mathrm{F}$ statistics
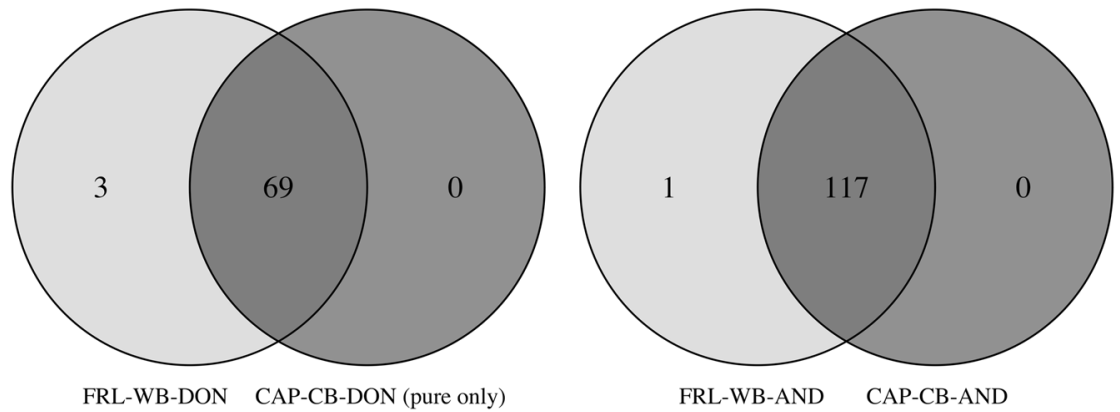

Fig. 1 Comparison of the number of alleles (after removing singletons) between each captive wild-born set (CAP-WB) and its respective source population (FRL-WB). Left: Doñana population (DON); right:

These slightly negative values suggest that variance is higher within than between groups.

In summary, lack of structure between founders and their source population indicate that both genetic stocks are reasonably well represented in captivity, whereas diversity statistics suggest a slightly incomplete representation of wild allelic variation in founders from DON.

\section{Optimal and realised ancestry proportion among founders and theoretical maximum $\mathrm{H}_{\mathrm{E}}$}

According to theoretical predictions, and given the unbiased expected homozygosity of each genetic stock (DON: 0.703; AND: 0.541) and observed Nei's minimum distance between the two (0.3), a proportion of 0.36 founders from DON and 0.64 from AND ( 1:2 DON:AND) would yield the theoretical maximum $\mathrm{H}_{\mathrm{E}}$ of 0.54 (Supplementary Figure S3). The actual proportion of founders from each remnant population has changed over the years and is approachingbut has not yet reached - this optimum, showing a relative deficit of CAP-WB-DON individuals for most of the study
Andújar population (AND). Four admixed CAP-WB-DON individuals

period (Supplementary Figure S4). This may have contributed to a realised $\mathrm{H}_{\mathrm{E}}$ a little below the theoretical maximum at the end of the study period (see below).

\section{Molecular estimation of relatedness among CAP-WB individuals}

Relatedness values among CAP-WB individuals are reported in Supplementary Table S3. Average R was notable ( $\mathrm{R}=0.098$ after excluding self-relatedness). The actual distribution exhibited a marked bimodality, in which the mode closer to zero amassed relatedness between DON and AND individuals and the higher mode encompassed relatedness within each genetic pool (Fig. 2). The subsequent shoulder and a long tail suggest the existence of certain pairs of moderately related founders within both stocks, but mainly within the DON subset.

To characterise relationships between founders better, we obtained maximum likelihood inferences of relatedness among pairs within each genetic CAP-WB stock using the observed allelic frequencies of each population were excluded 


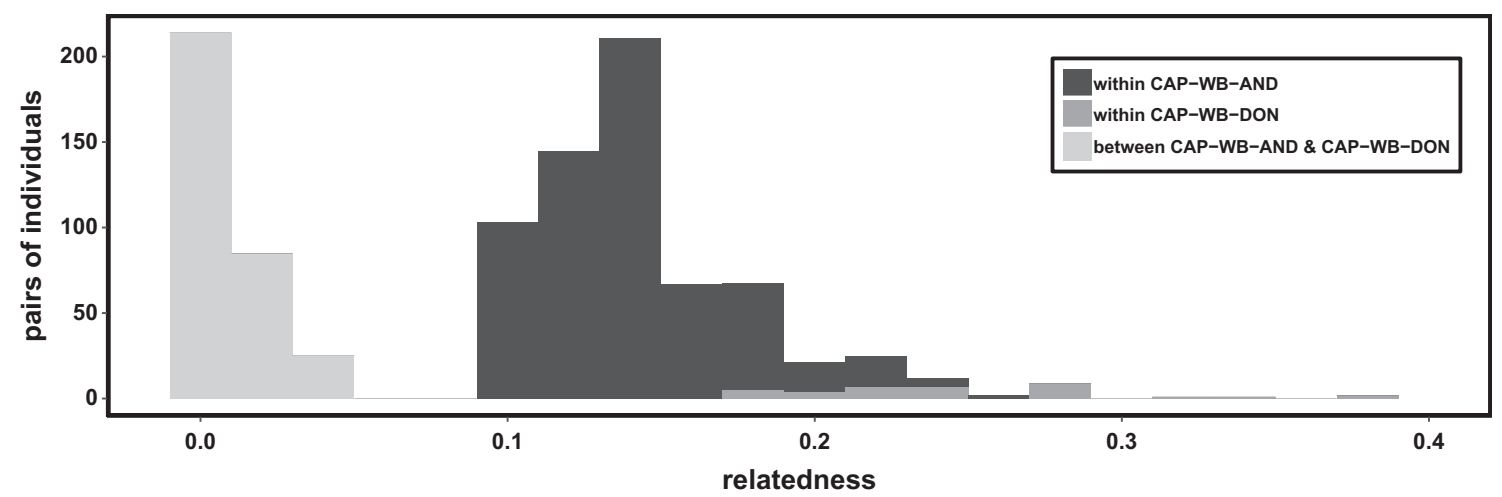

Fig. 2 Relatedness between pairs of CAP-WB individuals. Different shades of grey depict comparison within the AND subset, within the
DON subset, and between DON and AND individuals. CAP-WB captive wild-born individuals, DON Doñana, AND Andújar
(Supplementary Tables S4, S5). We obtained moderate levels of ambiguous kinship; in other words, many individuals could not be assigned unambiguously as unrelated or related, especially in the DON stock, where diversity was lower and relationships are known to be more complex (Lucena-Perez et al. 2018). Nevertheless, both stocks were confirmed to include a number of related pairs (resolved with a confidence of $95 \%$ ), including some instances of FS and PO relationships (Supplementary Figure S5).

\section{Evolution of diversity over the years}

\section{Molecular statistics}

Average $\mathrm{H}_{\mathrm{O}}$ of the CAP-CB cohorts fluctuated over the years, mostly driven by the degree of admixture of the two differentiated genetic stocks of DON and AND (Fig. 3a). $\mathrm{H}_{\mathrm{O}}$ peaked in years when most of the offspring were $F_{1}$, decreased later when successive generations of admixture (backcrosses) became more frequent, and then stabilised in more recent years around the theoretical maximum value for $\mathrm{H}_{\mathrm{E}} \cdot \mathrm{H}_{\mathrm{O}}$ consistently stayed above $\mathrm{H}_{\mathrm{E}}$, resulting in negative $F_{\text {IS }}$ throughout the entire history of the captive population, an expected outcome of the inbreeding avoidance strategy implemented by the genetic management programme, which has favoured the mating of least related couples (Fig. 3a, b).

The whole population (census approach) followed a pattern similar to that of cohorts: while $\mathrm{H}_{\mathrm{O}}$ exceeded $\mathrm{H}_{\mathrm{E}}$ in CAP-CB individuals, reaching higher values in years with a higher proportion of $\mathrm{F}_{1}$ individuals, CAP-WB individuals exhibited the opposite pattern, i.e., $\mathrm{H}_{\mathrm{E}}$-which seemed to flatten above 0.5 following the stabilisation of allelic frequencies-was higher than average $\mathrm{H}_{\mathrm{O}}$ (Fig. 4a, b). Since the CAP-WB group resulted from the pooling of two differentiated populations, such a Wahlund effect (Wahlund 1928) was expected. Consistent with this, global $F_{I S}$ for the whole CAP population was positive in the early phase of the ex situ programme (when CAP-WB was the major, or even only, component), and subsequently steadily decreased as the proportion of admixed individuals continued to increase, finally reaching a negative value in the last year of our study (Fig. 4c).

Regarding the structure between facilities in $2015, \mathrm{~F}_{\mathrm{ST}}$ values were low between all pairs of breeding facilities, although still significant for the Acebuche-Granadilla, Granadilla-Olivilla and Acebuche-Olivilla pairs. The highest value $(0.018 ; 99 \%$ CI [0.009-0.028]) was found between Acebuche and Granadilla, while the lowest (-0.005; 99\% CI [-0.012 to 0.001]) was observed for the Silves and Olivilla comparison (Supplementary Figure S6).

\section{Pedigree statistics}

GD increased swiftly in the first few years of the breeding programme as average kinship diminished with new recruitments, but stabilised from 2007 onwards at a value higher than 0.97 . When accounting for the empirical relatedness between founders, however, GD tends towards a value around 0.87 (Fig. 5a).

Under the assumption of zero relatedness between founders, the breeding programme has been able to keep inbreeding at bay $\left(\mathrm{F}<10^{-4}\right.$ up to 2015). When considering molecular kinships, however, the picture is starkly different (Fig. 5b). In earlier years values up to $\sim 0.2$ were reached, likely reflecting recruitment of wild-born individuals with varying degrees of inbreeding. In later years, inbreeding has fluctuated around 0.1 .

\section{Discussion}

Since its inception in 2003, the Iberian lynx ex situ programme has become a major pillar on which conservation efforts to save the species from extinction rest. Although 
Fig. 3 Evolution of diversity and inbreeding statistics over time for each year's CAP-CB births (cohorts approach). a observed heterozygosity $\left(\mathrm{H}_{\mathrm{O}}\right)$ and expected heterozygosity $\left(\mathrm{H}_{\mathrm{E}}\right)$; dashed lines represent the theoretical maximum $\mathrm{H}_{\mathrm{E}}(\mathrm{OPT})$, and each FRL-WB population's $\mathrm{H}_{\mathrm{E}}$. b fixation index $\left(\mathrm{F}_{\mathrm{IS}}\right)$; the dashed line indicates $\mathrm{F}_{\mathrm{IS}}=0$. DON Doñana, AND Andújar
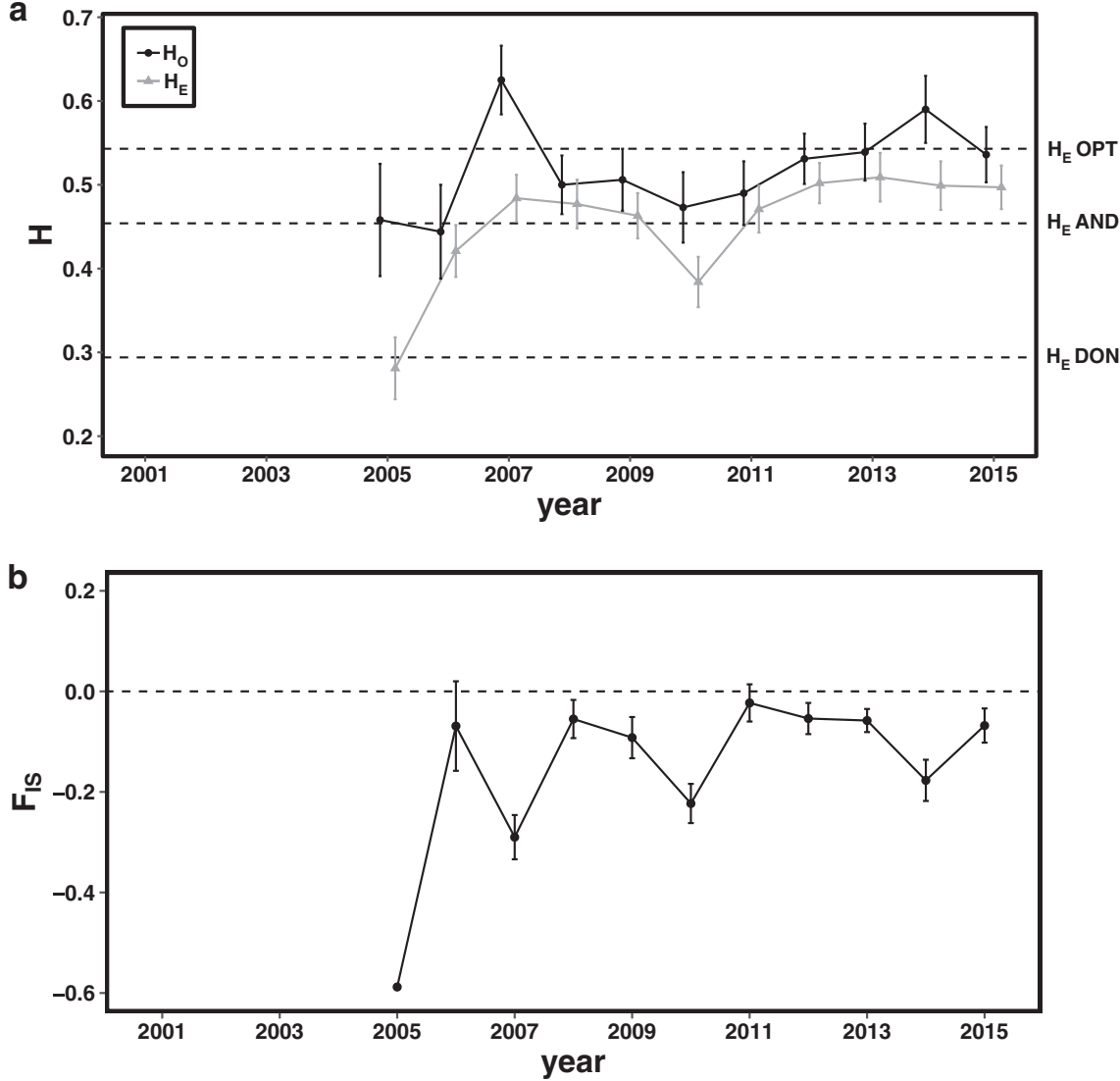

its course of action has been clearly validated in demographic terms, evaluating its success from a genetic point of view is not as straightforward. A thorough study was necessary to either back the adopted set of measures and decisions or shed light on potential concerns or amendable issues. In this study, we discovered that the species' remnant genetic diversity is fairly well represented in the CAP population, more so for the AND genetic background than for the DON one. Considering that the heterozygosity of the CAP population has been approaching the theoretical maximum level, and its mean inbreeding has been constantly shrinking, the programme's genetic management has been satisfactory. Moreover, differentiation between breeding facilities is also negligible. In short, the programme has thus far been able to achieve its goals from a genetic perspective.

\section{To mix or not to $\mathrm{mix}$}

A first important decision to be made when genetically differentiated populations persist is whether to mix them and manage them as a single unit or to keep them separated in captivity. In those cases where remnant populations have different local adaptations or a long history of isolation, mixing stocks could potentially lead to a reduction in the biological fitness of the hybrid offspring (outbreeding depression) due to extrinsic or intrinsic factors (Templeton 1986; Lynch 1991). In contrast, when differentiation is due to stochastic processes, and/or when the risk of inbreeding in the source populations far outweighs the risk of outbreeding, mixing affords the potential advantages of maximising genetic diversity and boosting fitness of hybrid individuals (Chesser 1983; Lacy 1987). For the Iberian lynx ex situ programme, it was decided that the two remnant populations of DON and AND should be mixed in order to restore the highest possible amount of historical diversity and to limit inbreeding depression. This decision, originally informed by accumulated signs of inbreeding depression (Peña et al. 2006; Jiménez et al. 2008; Palomares et al. 2012; Ruiz-López et al. 2012) and historical range reconstructions showing likely connections in the recent past, has recently been further validated by an extensive analysis of the historical variation in the species, which showed a progressive loss of genetic diversity within populations and the accumulation of genetic differentiation among them, resulting from the contraction and fragmentation that took place in the latter half of the 20th century (Casas-Marce et al. 2017). Even though the estimated date of divergence of the two remnant populations (ca. $200 \mathrm{ybp}$ ) was earlier than previously thought based on range reconstructions 
Fig. 4 Evolution of diversity statistics over time for each year's total population (census approach). a observed

heterozygosity $\left(\mathrm{H}_{\mathrm{O}}\right)$; dashed lines represent the theoretical maximum $\mathrm{H}_{\mathrm{E}}(\mathrm{OPT})$ and each FRL-WB population's $\mathrm{H}_{\mathrm{E}}$. b expected heterozygosity $\left(\mathrm{H}_{\mathrm{E}}\right)$, with the same dashed lines as in a. c fixation index $\left(\mathrm{F}_{\mathrm{IS}}\right)$; the dashed line indicates $\mathrm{F}_{\mathrm{IS}}=0$. CAP captive population, CAPCB captive-born individuals, CAP-WB captive wild-born individuals, FRL-WB free-living wild-born individuals, DON Doñana, AND Andújar
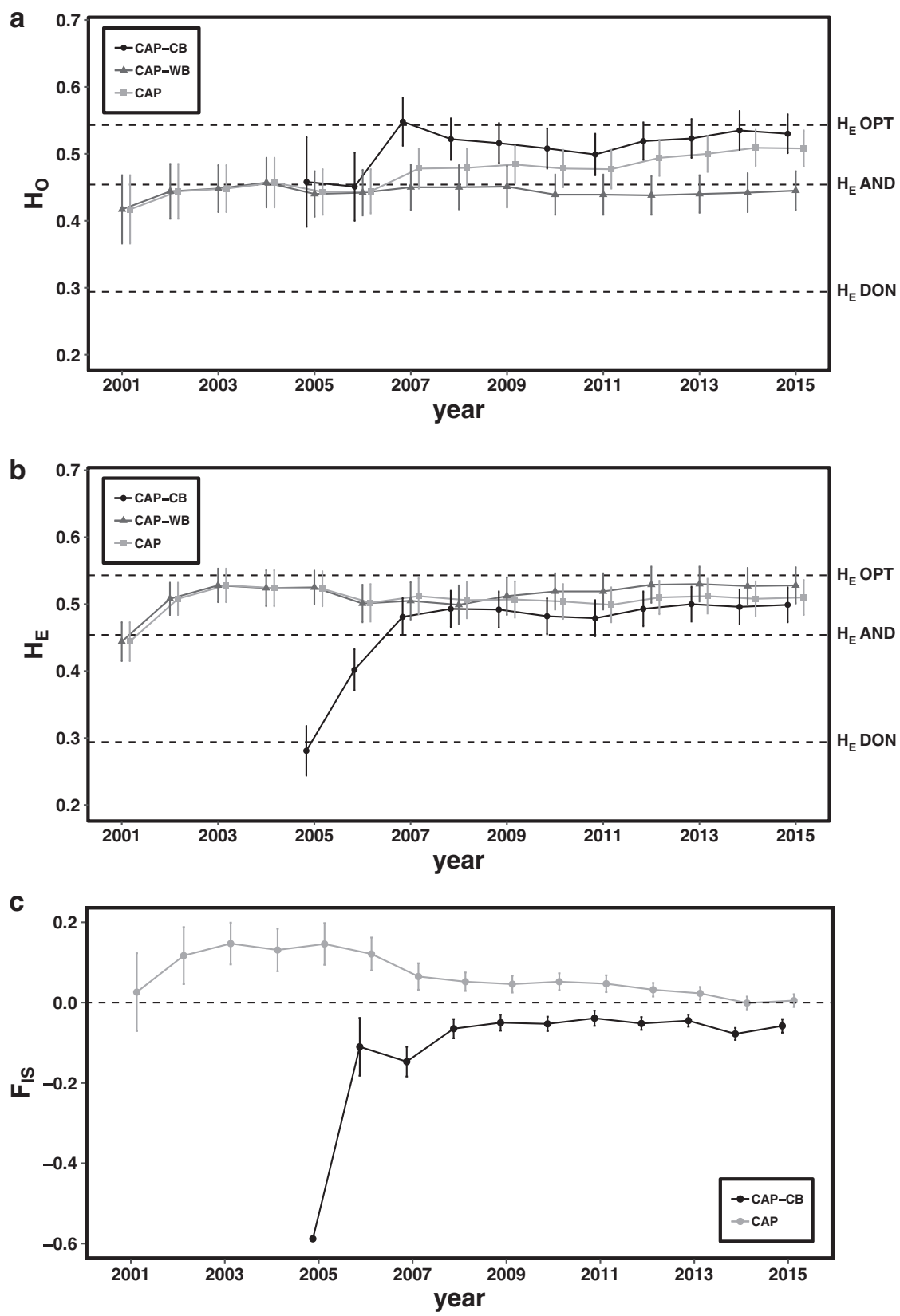

(around $50 \mathrm{ybp}$ ), the absence of major environmental differences and the evidence of gene flow in the recent past do conclusively support the management of the two remnant populations as a single unit in captivity as well as in the wild (Frankham et al. 2011). These points also validate the genetic reinforcement of DON through the translocation of animals from AND, which was initiated in 2007 (Simón et al. 2012).

The fitness consequences of admixture in the Iberian lynx have not been formally analysed yet, but as often observed (e.g., Frankham 2016), the fitness of outbred individuals coming from admixture of the two inbred lines appears to be higher, and at the very least it is not lower than that of their pure, inbred counterparts, both in captivity and in the wild (Simón et al. 2012).

\section{Representativeness}

One of the main goals of ex situ conservation is to safeguard genetic diversity of threatened species or populations, and so capturing as much of that variation as possible should be the first objective. Both genetic stocks of DON and AND seem to have been represented well in captivity, as revealed by our analyses on private alleles and particularly by the extremely low $\mathrm{F}_{\mathrm{ST}}$ values between each founder subset and their source population. As expected, our results suggest 
Fig. 5 Evolution of pedigreebased diversity and inbreeding statistics over time when enabling $(\mathrm{ON})$ or not enabling (OFF) the empirical kinship matrix. a genetic diversity (GD); b inbreeding coefficient $(\mathrm{F})$
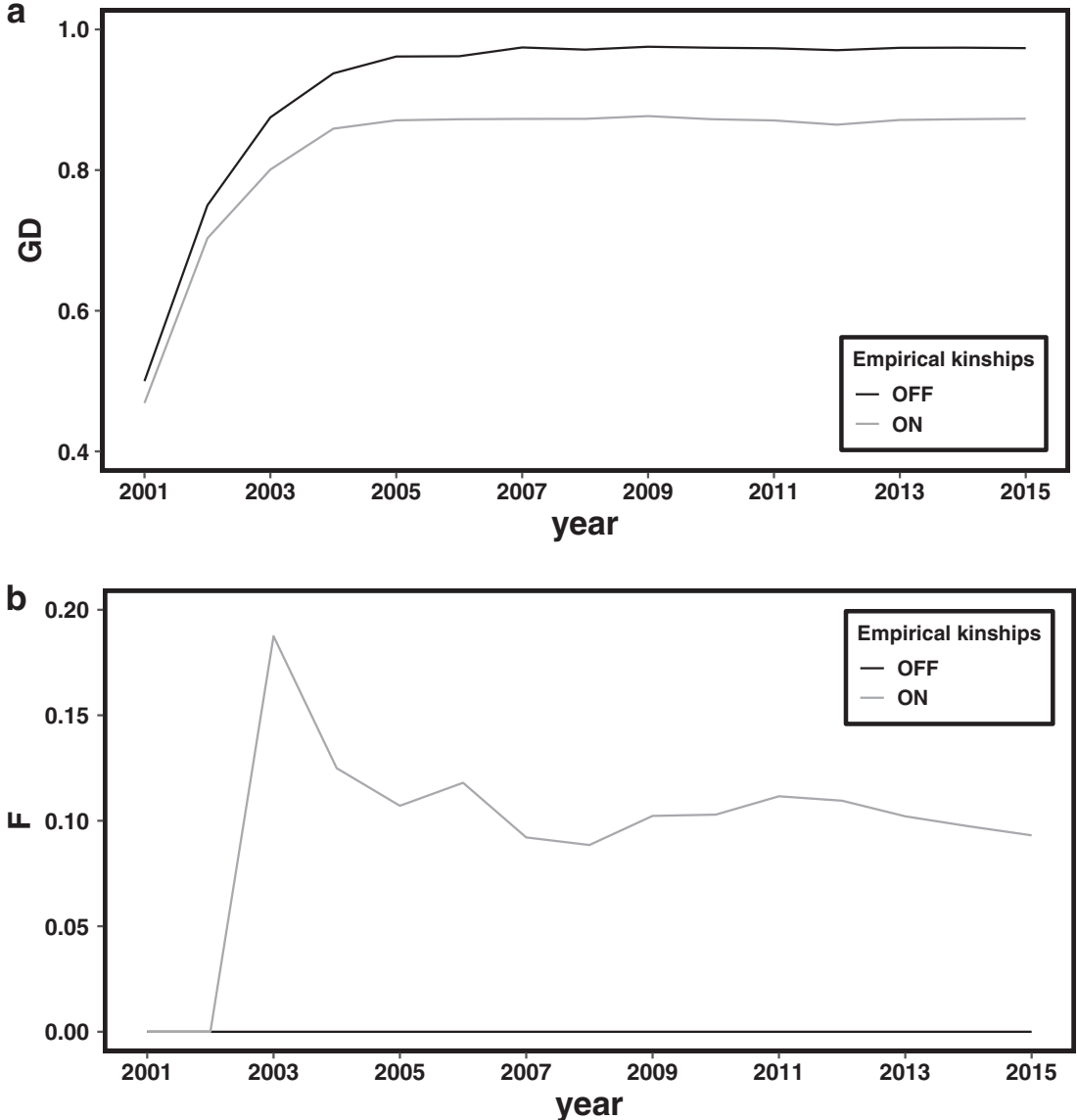

that of the two CAP-WB stocks, the smaller CAP-WBDON ( $N=9$ pure and 4 backcross individuals) provides a slightly worse representation of its source than its counterpart from AND $(N=36)$, as indicated by its higher proportion of unsampled alleles (Fig. 1) and significant differences in NA and AR (Table 1). Thus, recruiting pure DON individuals should be a priority in the near future. On the other hand, once a source population is well represented genetically, as is now the case for SMO, randomly selected new founders will likely make a relatively small contribution to the global genetic diversity and may rank low in breeding priority. Given this situation, together with current space limitations, carefully selecting potential founders based on their average kinship to the current captive population becomes a priority.

A related but different matter concerns the proportions in which the two genetic stocks should be mixed in captivity, considering the difference in their genetic diversity and the level of genetic differentiation observed between them. Our estimated optimal contribution of about two AND lynx for every DON individual ( 0.64 vs. 0.36 ) has not quite yet been realised, as the AND stock has been overrepresented since 2003 to the detriment of the DON one. Empirical proportions did approach the optimal ones in the last few years of the study ( 0.71 vs. 0.29 in 2015 , when they were the closest), and do so even more at present (data not shown), so it is expected that the $\mathrm{H}_{\mathrm{E}}$ of the captive population will continue to close in on the theoretical maximum in the near future. For the time being, this observation underlines the importance of prioritising DON founders versus AND ones in the short-term.

\section{Effectiveness of genetic management}

Management in ex situ conservation programmes typically invokes pedigree-based kinships assuming unrelated founders. However, such an assumption dismisses the possible genetic structure between, and kinship structure within, the source populations (e.g., Astle and Balding 2009), which are common situations when dealing with recently declined and fragmented populations, such as those of the Iberian lynx. Molecular markers, on the other hand, can provide insights into these processes, and marker-based relatedness estimators have been developed specifically for structured populations (Oliehoek et al. 2006). Microsatellite genotypes have been previously used in breeding programmes to augment pedigree-based management (Jones et al. 2002; Gonçalves Da Silva et al. 2010; Henkel et al. 2012), while 
more recently, SNP-derived kinships have informed the genetic management of the whooping crane (Grus americana; Boardman et al. 2017) and Tasmanian devil (Sarcophilius harissii; Hogg et al. 2017). Unfortunately, these are among the few existing examples of direct usage of molecular kinships within breeding programmes (Norman et al. 2019).

Currently, the Iberian lynx captive population is genetically managed using a mixture of both pedigree- and molecular-based approaches, where kinships among all founders are estimated based on genotypes for the 36microsatellite set, and pedigree-based kinships are calculated for the remainder of the population taking the estimated founder kinships into consideration. Here, we found moderate levels of relatedness among founders, evidence of the recent structure within both wild populations, and particularly in DON. It is therefore likely that a hypothetical alternative management assuming unrelated founders would have yielded a suboptimal outcome. The results from PMx show that ignoring relationships between founders can lead to a gross overestimation of GD and underestimation of mean inbreeding in the population. To be more specific, under the assumption of zero relatedness among founders, no inbreeding accumulated during the period of our study, but when the empirical matrix is accounted for, the average population inbreeding fluctuated around a non-negligible value of 0.1 (Fig. 5). It must be noted that ignoring relatedness among founders will generally lead to the underestimation of inbreeding for any given genealogy, but more importantly, to suboptimal mating schemes (i.e., a different genealogy) that would result in an otherwise avoidable accumulation of inbreeding. Overall, our findings argue against the founder assumption whenever a certain level of inbreeding and/or relatedness among founders cannot be discarded, as typically occurs in admixed captive populations.

In such instances, a natural consequence of applying a minimum kinship-based strategy is that genetic structure between the two (or more) source populations weighs heavily in the design of the matings, so interpopulation crosses that generate hybrids are often favoured.

Genetic management in breeding programmes should be planned in advance. Particularly, the consideration of kinship among founders is most necessary at an early stage, as allelic frequencies in a population managed by minimum mean kinship equalise after four to five generations, so that information on founder relationships may not have any significant effect on genetic trends at these later stages (Schäfer and Reiners 2017).

Molecular kinship holds the convenience of reflecting realised instead of average expected kinship; however, it has been argued to be preferable to genealogical information only when estimated from high-density molecular data (Gómez-Romano et al. 2013; Kardos et al. 2015). Indeed, estimates of relatedness and other genetic parameters based on a limited number of hypervariable markers such as microsatellites have been argued to have high sampling variances and can be inaccurate (Blouin et al. 1996; Csilléry et al. 2006), particularly so in genetically eroded populations (Tokarska et al. 2009). However, our set of 36 microsatellites, which is larger than the average size used in wildlife studies (Witzenberger and Hochkirch 2011), has a low overall genotype error rate as judged by the small proportion of Mendelian errors in the pedigree, and holds moderate power to classify individuals in kinship categories, properly discriminating full-siblings from halfsiblings in $75 \%$ of the cases and from unrelated individuals in over $99 \%$ of them (Kleinman-Ruiz et al. 2017). Furthermore, we only used molecular information to assess the relatedness among founders, for which no genealogy is available, but relied on the fully known genealogy otherwise.

The Iberian lynx ex situ programme is arranged in breeding facilities as a security measure in case of catastrophes. Since matings are performed within centres, genetic management also pursues the minimisation of genetic structure among the facilities to restrict the rise of inbreeding. The nearly negligible but still significant levels of structure that we observe here support the maintenance of translocations of individuals at current or even slightly higher levels.

\section{Needs, challenges and recommendations}

Deleterious traits with a likely genetic basis are a pervasive challenge for ex situ conservation programmes (Laikre 1999 and the references therein), and the Iberian lynx' is no exception. Idiopathic epilepsy occurring at moderate frequency in captivity causes a number of cubs at the age of around 2 months to go through episodes of seizures and eventually die unless treated (Martínez et al. 2013). Its segregation pattern suggests a simple genetic basis with recessive inheritance, but without further knowledge, management of this trait has consisted of excluding affected individuals from the pool of breeders, and avoiding crosses between any two identified carriers. Not only can these restrictions interfere with minimum kinship breeding recommendations, but they also imply a general lessening of the breeding programme's performance as unbreedable individuals add up and occupy more enclosures. While relocating this surplus to external parties (such as zoos) can alleviate the saturation, it does not tackle the root cause of 
the problem. Further research is encouraged to narrow down the cause of this and other genetic disorders, such as cryptorchidism, and to identify carriers molecularly with the objective of incorporating selection measures against the responsible alleles, as is being done to manage chondrodystrophy in the California condor (Ryder et al. 2016).

Beyond its role as an insurance population, the Iberian lynx ex situ population has also provided the majority of individuals for reintroduction. Between 2010 and 2017, a total of six populations were founded across the southern half of the Iberian Peninsula by sub-adults released from captivity on a yearly basis. Under these circumstances, it is necessary to strike a balance between the number (and composition) of released and kept individuals, in order to neither distort the age pyramid nor the allelic frequencies of the insurance population. Moreover, since all reintroduced populations are meant to be representative of the captive stock and, eventually, act as a single metapopulation, the distribution of individuals among release sites should ideally be based on up-to-date allelic frequencies and/or genealogical data at each site. This scenario requires an intensive and integrative individual-based genetic monitoring that records survival, reproduction and dispersal in all reintroduced populations. To fulfil this requirement, current practices based on camera-trapping and radio and GPS telemetry should be complemented with non-invasive genetic monitoring, which would allow for the assessment of progress towards the final objectives of the interactive in situ/ex situ strategy (Attard et al. 2016).

Following the publication of the Iberian lynx genome (Abascal et al. 2016), small panels of optimal, genome-wide SNPs were selected based on the allelic frequencies of the captive population and compared to the set of 36 microsatellites upon which genetic management of the species has relied so far (Kleinman-Ruiz et al. 2017). According to this study, these SNP panels provide more power than the current 36-microsatellite panel to carry out routine conservation tasks, such as the identification of individuals, parentage assignment or relatedness estimation, and they are also best suited for application to non-invasive samples. Hence, they are positioned as the most convenient and effective tool on which to base the genetic monitoring and integrative management of all Iberian lynx populations in the future.

It is important to keep in mind that ex situ conservation strategies involve huge resource investments (Conway 1986), which many authors argue should rather be diverted into in situ measures (Caughley 1994; Snyder et al. 1996). Moreover, ex situ actions will not be applicable to most threatened species (Rahbek 1993; Balmford et al. 1995; Snyder et al. 1996). Yet the IUCN's Conservation Breeding Specialist Group have recommended captive breeding for one-third of vertebrate taxa at risk of extinction (Seal et al.
1994). The opportunity, feasibility and priority of an ex situ conservation programme should be considered carefully case by case, and when implemented, it must be scientifically managed and integrated into a multifaceted species conservation plan (Russello and Amato 2007; Bowkett 2009).

The Iberian lynx ex situ breeding programme has been a key piece in the multifaceted conservation of the Iberian lynx. After 12 years, it has accomplished the two main goals that were set at the start. Firstly, it has succeeded in establishing a demographically and genetically healthy ex situ population that may act as a safeguard for the species in case of extinction in the wild. Secondly, after a few years of internal growth, the population has been serving as the almost exclusive source of individuals for reintroduction in the wild. Besides, the programme has assembled a set of experts in many different fields as well as fostered and coordinated research on issues of high relevance for the conservation of the species, while becoming a major driver of awareness and dissemination. Here, we show how the Iberian lynx ex situ programme has been quite effective in representing, boosting and maintaining the low genetic diversity that survived the latest severe bottleneck of the species while minimising the accumulation of inbreeding, which should ultimately result in increased adaptive potential and average fitness. In this regard, the Iberian lynx ex situ programme could serve as an example of markerassisted pedigree-based management for other species at similar conservation stages.

\section{Data archiving}

The datasets analysed in this study are available in our institutional repository DIGITAL.CSIC (https://doi.org/10. 20350/digitalCSIC/8624).

Acknowledgements Iberian lynx samples were contributed by the Iberian lynx Ex Situ Breeding Programme, the Centro de Análisis y Diagnóstico de la Fauna Silvestre and the LIFE projects LIFE06NAT/ E/000209 and LIFE10NAT/ES/570, with authorisation of the Consejería de Medio Ambiente de la Junta de Andalucía. Logistical support was provided by the Laboratorio de Ecología Molecular, Estación Biológica de Doñana, CSIC (LEM-EBD). The study was funded by the contract between the CSIC and the Consejería de Medio Ambiente de la Junta de Andalucía "Caracterización genética de individuos y poblaciones andaluzas de lince ibérico" and by the Spanish Dirección General de Investigación Científica y Técnica through projects CGL2006-10853/BOS, CGL2010-21540/BOS, CGL2013-47755-P, and CGL2017-84641-P. DKR was supported by a PhD contract from the Programa Internacional de Becas "La Caixa-Severo Ochoa". MCM was supported by a PhD JAE grant from the CSIC (Spanish National Research Council). CS was supported by a Ciência Sem Fronteiras grant from the CNPq (Brazilian National Research Council). Special thanks to David Aragonés from Laboratorio de Sistemas de Información Geográfica y Teledetección, Estación Biológica de Doñana, CSIC (LAST-EBD) for his help with the map, and to P. James Macaluso Jr. for his assistance in the English editing of the paper. We appreciate 
useful comments and suggestions from Maria Lucena-Perez, Elena Marmesat, Ana Píriz and three anonymous reviewers.

\section{Compliance with ethical standards}

Conflict of interest The authors declare that they have no conflict of interest.

Publisher's note: Springer Nature remains neutral with regard to jurisdictional claims in published maps and institutional affiliations.

\section{References}

Abascal F, Corvelo A, Cruz F, Villanueva-Cañas JL, Vlasova A, Marcet-Houben M et al. (2016) Extreme genomic erosion after recurrent demographic bottlenecks in the highly endangered Iberian lynx. Genome Biol 17:251

Adamack AT, Gruber B (2014) PopGenReport: simplifying basic population genetic analyses in R. Methods Ecol Evol 5:384-387

Astle W, Balding DJ (2009) Population structure and cryptic relatedness in genetic association studies. Stat Sci 24:451-471

Attard CRM, Möller LM, Sasaki M, Hammer MP, Bice CM, Brauer CJ et al. (2016) A novel holistic framework for genetic-based captivebreeding and reintroduction programs. Conserv Biol 30:1060-1069

Ballou JD, Lacy RC (1995) Identifying genetically important individuals for management of genetic diversity in pedigreed populations. In: Ballou JD, Gilpin M, Foose TJ (eds) Population management for survival and recovery. Columbia University Press, New York, pp 76-111

Ballou JD, Lees C, Faust LJ, Long S, Lynch C, Lackey LB, et al. (2010) Demographic and genetic management of captive populations. In: Kleiman DG, Thompson K, Kirk-Baer C (eds) Wild mammals in captivity, principles and techniques. University of Chicago Press, London \& Chicago, pp 219-252

Balmford A, Leader-Williams N, Green MJB (1995) Parks or arks. Biodivers Conserv 4:595-607

Blouin MS, Parsons M, Lacaille V, Lotz S (1996) Use of microsatellite loci to classify individuals by relatedness. Mol Ecol 5:393-401

Boardman K, Mace M, Peregoy S, Ivy JA (2017) Population analysis $\&$ breeding transfer plan, whooping crane (Grus americana). AZA Species Survival Plan ${ }^{\circledR}$ Program. Population Management Center, Association of Zoos and Aquariums, Silver Spring, MD, $36 \mathrm{pp}$

Bowkett AE (2009) Recent captive-breeding proposals and the return of the ark concept to global species conservation. Conserv Biol 23:773-776

Butchart SHM, Walpole M, Collen B, van Strien A, Scharlemann JPW, Almond REA et al. (2010) Global biodiversity: Indicators of recent declines. Science 328:1164-1168

Caballero A, Toro MA (2000) Interrelations between effective population size and other pedigree tools for the management of conserved populations. Genet Res 75:331-343

Calzada J, Guzmán JN, Rodríguez A (2007).Lynx pardinus (Temminck, 1827). Ficha libro rojo. In: Palomo L, Gisbert J, Blanco J (eds) Atlas y libro rojo de los mamíferos terrestres de España. Dirección General para la Biodiversidad-SECEM-SECEMU, Madrid, pp 345-347

Casas-Marce M, Marmesat E, Soriano L, Martínez-Cruz B, LucenaPerez M, Nocete F et al. (2017) Spatiotemporal dynamics of genetic variation in the Iberian lynx along its path to extinction reconstructed with ancient DNA. Mol Biol Evol 34:2893-2907
Casas-Marce M, Soriano L, López-Bao JV, Godoy JA (2013) Genetics at the verge of extinction: insights from the Iberian lynx. Mol Ecol 22:5503-5515

Caughley G (1994) Directions in conservation biology. J Anim Ecol 63:215-244

Chen H, Boutros PC (2011) VennDiagram: a package for the generation of highly-customizable Venn and Euler diagrams in R. BMC Bioinform 12:12-35

Chesser RK (1983) Isolation by distance: relationship to management of genetic resources. In: Schonewald-Cox C, Chambers S, MacBryde B, Thomas W (eds) Genetics and conservation: a reference for managing wild animal and plant populations. Benjamin Cummings Publishing Co., London, UK, pp 66-77

Conway WG (1986) The practical difficulties and financial implications of endangered species breeding programmes. Int Zoo Yearb $24: 210-219$

Csilléry K, Johnson T, Beraldi D, Clutton-Brock T, Coltman D, Hansson B et al. (2006) Performance of marker-based relatedness estimators in natural populations of outbred vertebrates. Genetics 173:2091-2101

Dobrynin P, Liu S, Tamazian G, Xiong Z, Yurchenko AA, Krasheninnikova K et al. (2015) Genomic legacy of the African cheetah, Acinonyx jubatus. Genome Biol 16:277

Fernández BJ, Toro MA (1999) The use of mathematical programming to control inbreeding in selection schemes. J Anim Breed Genet 116:447-466

Fernández J, Toro MA (2006) A new method to estimate relatedness from molecular markers. Mol Ecol 15:1657-1667

Fernández J, Toro MA, Caballero A (2004) Managing individuals' contributions to maximize the allelic diversity maintained in small, conserved populations. Conserv Biol 18:1358-1367

Frankham R (2008) Genetic adaptation to captivity in species conservation programs. Mol Ecol 17:325-333

Frankham R (2016) Genetic rescue benefits persist to at least the F3 generation, based on a meta-analysis. Biol Conserv 195:33-36

Frankham R, Ballou JD, Briscoe DA (2010). Introduction to conservation genetics, 2nd edn. Cambridge University Press, Cambridge

Frankham R, Ballou JD, Eldridge MDB, Lacy RC, Ralls K, Dudash MR et al. (2011) Predicting the probability of outbreeding depression. Conserv Biol 25:465-475

Godoy JA, Casas-Marce M, Fernández J (2009) Genetic issues in the implementation of the Iberian lynx ex situ conservation programme. In: Vargas A, Breitenmoser C, Breitenmoser U (eds) Iberian lynx ex situ conservation: an interdisciplinary approach, Fundación Biodiversidad: Madrid, pp 86-99

Gómez-Romano F, Villanueva B, de Cara MA, Fernández J (2013) Maintaining genetic diversity using molecular coancestry: the effect of marker density and effective population size. Genet Sel Evol 45:38

Gonçalves Da Silva A, Lalonde DR, Quse V, Shoemaker A, Russello MA (2010) Genetic approaches refine ex situ lowland tapir (Tapirus terrestris) conservation. J Hered 101:581-590

Goudet J (1995) FSTAT (version 1.2): a computer program to calculate F-statistics. J Hered 86:485-486

Goudet J (2002) FSTAT, a program to estimate and test gene diversities and fixation indices (version 2.9.3). https://www2.unil.ch/ popgen/softwares/fstat.htm

Guzmán JN, García FJ, Garrote G, Pérez de Ayala R, Iglesias C (2004) El lince ibérico (Lynx pardinus) en España y Portugal. Censo diagnóstico de sus poblaciones. Dirección General para la Biodiversidad, Madrid 
Henkel JR, Jones KL, Hereford SG, Savoie ML, Leibo SP, Howard JJ (2012) Integrating microsatellite and pedigree analyses to facilitate the captive management of the endangered Mississippi sandhill crane (Grus canadensis pulla). Zoo Biol 31:322-335

Hoffmann M, Hilton-Taylor C, Angulo A, Böhm M, Brooks TM, Butchart SHM et al. (2010) The impact of conservation on the status of the world's vertebrates. Science 330:1503-1509

Hogg CJ, Grueber CE, Pemberton D, Fox S, Lee AV, Ivy JA et al. (2017) "Devil Tools \& Tech": a synergy of conservation research and management practice. Conserv Lett 10:133-138

Jiménez MA, Sánchez B, Alenza MDP, García P, López JV, Rodríguez A et al. (2008) Membranous glomerulonephritis in the Iberian lynx (Lynx pardinus). Vet Immunol Immunopathol 121:34-43

Johnson WE, Godoy JA, Palomares F, Delibes M, Fernandes M, Revilla E et al. (2004) Phylogenetic and phylogeographic analysis of Iberian lynx populations. J Hered 95:19-28

Jones KL, Glenn TC, Lacy RC, Pierce JR, Unruh N, Mirande CM et al. (2002) Refining the whooping crane studbook by incorporating microsatellite DNA and leg-banding analyses. Conserv Biol 16:789-799

Jost L (2008) GST and its relatives do not measure differentiation. Mol Ecol 17:4015-4026

Kalinowski ST, Taper ML, Marshall TC (2007) Revising how the computer program CERVUS accommodates genotyping error increases success in paternity assignment. Mol Ecol 16:1099-1106

Kalinowski ST, Wagner AP, Taper ML (2006) ML-RELATE: a computer program for maximum likelihood estimation of relatedness and relationship. Mol Ecol Notes 6:576-579

Kardos M, Luikart G, Allendorf FW (2015) Measuring individual inbreeding in the age of genomics: marker-based measures are better than pedigrees. Heredity (Edinb) 115:63-72

Kleinman-Ruiz D, Martínez-Cruz B, Soriano L, Lucena-Perez M, Cruz F, Villanueva B et al. (2017) Novel efficient genome-wide SNP panels for the conservation of the highly endangered Iberian lynx. BMC Genomics 18:556

Lacy RC (1987) Loss of genetic diversity from managed populations: interacting effects of drift, mutation, immigration, selection, and population subdivision. Conserv Biol 1:143-158

Lacy RC, Ballou JD, Pollak JP (2012) PMx: software package for demographic and genetic analysis and management of pedigreed populations. Methods Ecol Evol 3:433-437

Laikre L (1999) Hereditary defects and conservation genetic management of captive populations. Zoo Biol 18:81-99

Lucena-Perez M, Soriano L, López-Bao JV, Marmesat E, Fernández L, Palomares F et al. (2018) Reproductive biology and genealogy in the endangered Iberian lynx: implications for conservation. Mamm Biol 89:7-13

Lynch M (1991) The genetic interpretation of inbreeding depression and outbreeding depression. Evolution 45:622-629

Marshall TC, Slate J, Kruuk LEB, Pemberton JM (1998) Statistical confidence for likelihood-based paternity inference in natural populations. Mol Ecol 7:639-655

Martínez F, Manteca X, Pastor J (2013) Retrospective study of morbidity and mortality of captive Iberian lynx (Lynx pardinus) in the ex situ conservation programme (2004-june 2010). J Zoo Wildl Med 44:845-852

McGowan PJK, Traylor-Holzer K, Leus K (2017) IUCN guidelines for determining when and how ex situ management should be used in species conservation. Conserv Lett 10:361-366

Meuwissen TH (1997) Maximizing the response of selection with a predefined rate of inbreeding. J Anim Sci 75:934-940

Nei M (1973) Analysis of gene diversity in subdivided populations. Proc Natl Acad Sci 70:3321-3323
Norman AJ, Putnam AS, Ivy JA (2019) Use of molecular data in zoo and aquarium collection management: benefits, challenges, and best practices. Zoo Biol 38:106-118

Nowell K, Jackson P (1996) Wild cats: status survey and conservation action plan. IUCN/SSC Cat Specialist Group. IUCN, Gland

Oliehoek PA, Windig JJ, Van Arendonk JAM, Bijma P (2006) Estimating relatedness between individuals in general populations with a focus on their use in conservation programs. Genetics 173:483-496

Palomares F, Godoy JA, López-Bao JV, Rodríguez A, Roques S, Casas-Marce M et al. (2012) Possible extinction vortex for a population of Iberian lynx on the verge of extirpation. Conserv Biol 26:689-697

Peakall R, Smouse P (2012) GenAlEx 6.5: genetic analysis in excel. Population genetic software for teaching and research - an update. Bioinformatics 1:6-8

Peña L, Garcia P, Jiménez MA, Benito A, Pérez-Alenza MD, Sánchez B (2006) Histopathological and immunohistochemical findings in lymphoid tissues of the endangered Iberian lynx (Lynx pardinus). Comp Immunol Microbiol Infect Dis 29:114-126

Pimm SL, Jenkins CN, Abell R, Brooks TM, Gittleman JL, Joppa LN et al. (2014) The biodiversity of species and their rates of extinction, distribution, and protection. Science 344:1246752

Pritchard DJ, Fa JE, Oldfield S, Harrop SR (2012) Bring the captive closer to the wild: redefining the role of ex situ conservation. Oryx 46:18-23

Rahbek C (1993) Captive breeding - a useful tool in the preservation of biodiversity? Biodivers Conserv 2:426-437

Redford KH, Jensen DB, Breheny JJ (2012) Integrating the captive and the wild. Science 338:1157-1158

Rodríguez A, Calzada J (2015) Lynx pardinus. The IUCN Red List of Threatened Species. https://doi.org/10.2305/IUCN.UK.2015-2. RLTS.T12520A50655794.en

Rodríguez A, Delibes M (1992) Current range and status of the Iberian lynx Felis pardina Temminck, 1824 in Spain. Biol Conserv 61:189-196

Rodríguez A, Delibes M (2002) Internal structure and patterns of contraction in the geographic range of the Iberian lynx. Ecography (Cop) 25:314-328

Ruiz-López MJ, Gañán N, Godoy JA, Del Olmo A, Garde J, Espeso G et al. (2012) Heterozygosity-fitness correlations and inbreeding depression in two critically endangered mammals. Conserv Biol 26:1121-1129

Russello MA, Amato G (2007) On the horns of a dilemma: molecular approaches refine ex situ conservation in crisis. Mol Ecol 16:2405-2406

Ryder O, Miller W, Ralls K, Ballou JD, Steiner CC, Mitelberg A, et al. (2016) Whole genome sequencing of California condors is now utilized for guiding genetic management. In: International Plant and Animal Genome XXIV Conference, San Diego, CA, 8-13 January 2016

Sambrook J, Russell DW (2006) Purification of nucleic acids by extraction with phenol:chloroform. Cold Spring Harb Protoc 2006:pdb.prot4455

Schäfer F, Reiners TE (2017) Long term vs short term impact of founder relatedness on gene diversity and inbreeding within the European Endangered Species Programme (EEP) for the Nepalese red panda (Ailurus f. fulgens). J Zoo Aquarium Res 5:86-91

Seal US, Foose TJ, Ellis S (1994) Conservation Assessment and Management Plans (CAMPs) and Global Captive Action Plans (GCAPs). In: Olney PJ, Mace G, Feistner A (eds) Creative conservation: interactive management of wild and captive animals. Springer Netherlands, Dordrecht, pp 312-325

Simón MA, Gil-Sánchez JM, Ruiz G, Garrote G, Mccain EB, Fernández L et al. (2012) Reverse of the decline of the Endangered Iberian lynx. Conserv Biol 26:731-736 
Snyder NFR, Derrickson SR, Beissinger SR, Wiley JW, Smith TB, Toone WD et al. (1996) Limitations of captive breeding in endangered species recovery. Conserv Biol 10:338-348

Templeton A (1986) Coadaptation and outbreeding depression. In: Soule M (ed) Conservation biology. The science of scarcity and diversity. Sinauer Assoc, Sunderland, MA, pp 105-121

The R Core Team (2015) R: a language and environment for statistical computing. R Foundation for Statistical Computing, Vienna

Tokarska M, Marshall T, Kowalczyk R, Wójcik JM, Pertoldi C, Kristensen TN et al. (2009) Effectiveness of microsatellite and SNP markers for parentage and identity analysis in species with low genetic diversity: the case of European bison. Heredity (Edinb) 103:326-332

Toro MA, Caballero A (2005) Characterization and conservation of genetic diversity in subdivided populations. Philos Trans R Soc B Biol Sci 360:1367-1378

Vargas A, Breitenmoser C, Breitenmoser U (2009) Iberian lynx ex situ conservation: an interdisciplinary approach. Fundación Biodiversidad and International Union for Conservation of Nature,
Species Survival Commission (IUCN/SSC) Cat Specialist Group: Madrid

Vargas A, Rivas A, Sánchez I, Martínez F, Godoy JA, Roldán E et al. (2009) Iberian lynx conservation breeding program - update. Cat News 50:17

Vargas A, Sánchez I, Martínez F, Rivas A, Godoy JA, Roldán E et al. (2008) The Iberian lynx Lynx pardinus conservation breeding program. Int Zoo Yearb 42:190-198

Wahlund S (1928) Zusammensetzung von populationen und korrelationserscheinungen vom standpunkt der vererbungslehre aus betrachtet. Hereditas 11:65-106

Weir BS, Cockerham CC (1984) Estimating F-statistics for the analysis of population structure. Evolution $38: 1358-1370$

Wilson EO (1992) The diversity of life. Belknap Press, Cambridge

Witzenberger KA, Hochkirch A (2011) Ex situ conservation genetics: a review of molecular studies on the genetic consequences of captive breeding programmes for endangered animal species. Biodivers Conserv 20:1843-1861 